PENGELOLAAN ANGKUTAN KOTA DI INDONESIA

(Mohammad Benny Alexandri, Nurillah Novel)

\title{
PENGELOLAAN ANGKUTAN KOTA DI INDONESIA
}

\author{
Mohammad Benny Alexandri ${ }^{1}$, Nurillah Novel $^{2}$ \\ bennyalexandri@yahoo.co.id ${ }^{1}$; novelnurillah@gmail.com² \\ Fakultas Ilmu Sosial dan Ilmu Politik \\ Universitas Padjadjaran
}

\begin{abstract}
Abstrak
Tujuan penelitian ini adalah untuk mengetahui hambatan dan solusi permasalahan angkutan kota. Metode yang digunakan adalah kualitatif deskriptif dengan menganalisis pengalaman angkotan kota di Indonesia. Hasil. Penelitian ini juga melihat kondisi kualitas pelayanan angkutan kota. Hasil penelitian Berdasarkan dimensi tentang kualitas pelayanan angkutan kota yang disebutkan di atas antara lain keamanan, kenyamanan, kinerja \& kehandalan, kru dan kondisi kendaraan dan fasilitasnya. Artinya ada 5 (lima) aspek yang dinilai untuk mengetahui kualitas pelayanan angkutan kota, aspek keamanan dinilai dari keselamatan dalam perjalanan, keamanan dari tindakan criminal dalam perjalanan, serta keamanan dari perilaku penumpang lain. Sedangkan kenyamanan dilihat dari kenyamanan tempat duduk, tingkat kesesakan dalam kendaraan angkutan kota, dan kenyamannan temperature dalam kendaraan.
\end{abstract}

Kata Kunci : Angkutan Kota, kualitas pelayanan, kenyamanan, keselamatan, keamanan.

\section{Pendahuluan}

Angkutan Kota masih menjadi tumpuan bagi kalangan yang tidak memiliki akses dan kemampuan kendaraan pribadi. Hal ini sangat wajar karena tidak semua orang memiliki akses dan kemampuan terhadap kendaraan pribadi. Dengan demikian angkutan kota menjadi salah satu pilihan yang tepat untuk memenuhi kebutuhan alat transportasi yang dianggap terjangkau dengan jangkauan yang cukup luas.

Angkutan kota beroperasi sesuai dengan trayeknya masing-masing, biasanya mencakup jalanan utama dalam kota. Hal tersebut sangat memudahkan masyarakat untuk menjangkau wilayah-wilayah tujuan. Jumlahnya yang banyak dalam setiap trayek membuat masyarakat tidak perlu khawatir jika tertinggal angkutan kota yang sudah lewat. Meski tidak ada pathokan waktu khusus, masyarakat cukup fleksibel untuk mendapatkan layanan angkutan kota kapan saja dan dimana saja asalkan masih dalam trayek yang ditentukan.

Perkembangan berbagai alat transportasi, terutama berbasis aplikasi, tidak sepenuhnya mematikan angkutan kota. Berbagai keunggulan angkutan kota dari segi nilai ekonomis, daya tampung dan lainnya masih menjadi kekuatan yang harus dikembangkan agar dapat bertahan menghadapi persaingan.

\section{Reformasi Angkutan Umum Eksisting}

Reformasi angkutan umum yang ada saat ini dapat menjadi langkah awal untuk mendorong masyarakat menggunakan angkutan umum. Maksudnya, akibat perkembangan teknologi pada angkutan umum saat ini tidak dapat dipungkiri telah mengubah perilaku masyarakat yang serba aplikasi. Hal tersebut tentu saja mempengaruhi jumlah pengguna angkutan kota di berbagai daerah.

Meski masih ada penumpangnya, namun para sopir dan pengusaha angkutan kota mengeluhkan berkurangnya pendapatan dan setoran. Dengan demikian sangat perlu reformasi angkutan kota agar tidak hanya memenuhi standar kebutuhan masyarakat namun juga memberikan kepuasan layanan.

Di era saat ini, tuntutan terhadap kualitas layanan sangat penting. Sebab konsumen tidak lagi hanya fokus pada pemenuhan kebutuhan, tetapi juga kualitas layanan yang mampu memuaskannya. Apalagi dengan adanya banyak pilihan atau alternatif layanan tranportasi umum bagi konsumen dengan berbagai variasi harga dan layanan. Angkutan kota harus mulai membaiki kualitas layanannya. 
Terjadi upaya penolakan terhadap berkembangnya angkutan umum berbasis aplikasi di berbagai kota. Perseteruan secara pribadi maupun demo massal telah dilakukan oleh para pelaku ojek pangkalan dan sopir angkot. Tuntutannya dilatarbelakangi oleh dampak ekonomis dan psikologis yang mereka alami akibat munculnya angkutan berbasis aplikasi yang mengadakan promo besarbesaran hingga masyarakat beralih dari angkutan kota dan ojek ke ojek dan taksi online.

Dengan demikian perubahan angkutan kota harus segera dieksekusi mempertimbangkan bahwa bisnis dan layanan umum terus berkembang tidak dapat dihentikan. Bertahan dengan situasi yang ada hanya memperlambat kematian bisnis angkutan kota, namun mengikuti perubahan juga tidak serta merta menjanjikan kesuksesan yang instan. Adaptasi yang tinggi diperlukan dengan kesiapan mental dan semangat mempelajari hal baru.

Berdasarkan berbagai sumber dan survey khususnya di wilayah Bandung, banyak sopir dan pengusaha angkot yang mengeluhkan penurunan jumlah penumpang. Survey menyebutkan bahwa masyarakat berpendapat alasan-alasan mereka beralih dari angkot ke alat transportasi lain, khususnya yang berbasis aplikasi online. Alasan tersebut antara lain angkot dinilai tidak nyaman (secara fisik) yang maksudnya banyak di berbagai daerah kondisi kendaraan sudah tua dan banyak kerusakan fisik sana sini. Kemudian angkot juga dinilai relative tidak aman karena banyak berdatangan pedagang asongan dan pengamen, hal tersebut dianggap rawan pencopetan dan kejahatan lain. Selain itu angkot juga kini dinilai tidak efisien karena suka ngetem atau berhenti-berhenti menunggu penumpang. Kemacetan jalan yang memperlambat perjalanan diperparah dengan angkot yang sering berhenti atau ngetem demi menunggu penumpang.

\section{Tujuan Penelitian}

Tujuan penelitian ini adalah untuk mengetahui hambatan dan solusi permasalahan angkutan kota

\section{Metodologi}

Metodologi adalah kualitatif dan deskriptif dengan menggunakan indikator kualitas pelayanan untuk melihat kualitas layanan angkutan kota.

\section{Pembahasan}

Menurut Parasuraman, Zeithaml, dan Berry (1985), Wen dkk., Hu dan Jen, Perez, Sumaedi dkk. dinyatakan bahwa dimensi dan indicator kualitas pelayanan angkutan kota sebagai berikut ini:

Tabel 1. Dimensi dan Indikator Kualitas Layanan Angkutan Kota

\begin{tabular}{|c|c|}
\hline Dimensi & Indikator \\
\hline Ian & $\begin{array}{l}\text { - Keselamatan dalam perjalanan } \\
\text { - Keamanan dari tindakan kriminan ketika dalam } \\
\text { - } \text { Kerjalanan } \\
\text { Keamanan dari perilaku penumpang lainnya }\end{array}$ \\
\hline Kenyamanan & $\begin{array}{l}\text { - Kenyamanan tempat duduk } \\
\text { - } \text { Tingkat kesesakan dalam angkot } \\
\text { - } \text { Kenyamanan temperature dalam angkot }\end{array}$ \\
\hline Kinerja dan Kehandalan & $\begin{array}{ll}\text { - } & \text { Kinerja mesin } \\
\text { - } & \text { Waktu tunggu } \\
\text { - } & \text { Waktu perjalanan } \\
\text { - } & \text { Ketaatan terhadap peraturan }\end{array}$ \\
\hline Kru & - Kerapihan penampilan supir/kondektur \\
\hline
\end{tabular}




\begin{tabular}{|l|l|l|}
\hline & - Keinginan untuk membantu penumpang \\
& - Keinginan untuk menanggapi permintaan \\
& & penumpang \\
& - $\begin{array}{l}\text { Pemahaman terhadap kebutuhan peumpang } \\
\text { - Kesopanan supir/kondektur }\end{array}$ \\
\hline Kondisi Kendaraan dan Fasilitasnya & - Tampilan fasilitas dan peralatan angkot \\
& - Kebersihan eksterior angkot \\
& - Kebersihan interior angkot \\
& - Kebersihan dari coretan \\
\hline
\end{tabular}

Berdasarkan dimensi tentang kualitas pelayanan angkutan kota yang disebutkan di atas antara lain keamanan, kenyamanan, kinerja \& kehandalan, kru dan kondisi kendaraan dan fasilitasnya. Artinya ada 5 (lima) aspek yang dinilai untuk mengetahui kualitas pelayanan angkutan kota, aspek keamanan dinilai dari keselamatan dalam perjalanan, keamanan dari tindakan criminal dalam perjalanan, serta keamanan dari perilaku penumpang lain. Sedangkan kenyamanan dilihat dari kenyamanan tempat duduk, tingkat kesesakan dalam kendaraan angkutan kota, dan kenyamannan temperature dalam kendaraan. (Sik Sumaedi, Gede Bakti, Medi Yarmen (2012)).

Selanjutnya, kinerja dan kehandalan diukur dari kinerja mesin, waktu tunggu, waktu perjalanan dan ketaatan terhadap peraturan. Kemudian, aspek kru dinilai dari kerapihan penampilan sopir/kondektur, keinginan untuk membantu penumpang, keinginan untuk menanggapi permintaan penumpang, pemahaman terhadap kebutuhan penumpang serta kesopanan sopir/kondektur. Terakhir adalah aspek kondisi kendaraan dan fasilitasnya, yang dinilai adalah tampilan fasilitas dan peralatan angkutan kota, kebersihan eksterior dan interior angkutan kota, serta kebersihan dari coretan. Dengan demikian, target capaian pada restrukturisasi angkutan kota tentu saja agar dapat menjadikan 5 aspek dimensi beserta indikatornya di atas pada tingkat prima. Yaitu kondisi angkota kota yang aman, nyaman, andal, professional dan kendaraan serta fasilitas yang memadai. (Sik Sumaedi, Gede Bakti, Medi Yarmen (2012)).

\section{Pengelolaan Angkutan Kota Di Berbagai}

\section{Daerah}

Sebagai wawasan perlu mengetahui dan mempelajari bagaimana pengelolaan angkutan kota di berbagai daerah dengan berbagai latar belakang masalah yang berbeda. Namun sebelumnya akan disajikan beberapa hasil survey mengenali penyebab anjloknya bisnis angkutan umum dan bagaimana peluang angkutan kota untuk bangkit kembali.

Penyebab anjloknya bisnis angkutan umum:

1. Trayek angkutan kota tidak lagi mampu mengakomodasi kebutuhan masyarakat. Kini mobilitas masyarakat kian tinggi dalam waktu yang begitu cepat. Bahkan yang diharapkan masyarakat penjemputan transportasi umum tidak lagi dari shuttle ke shuttle, tapi dari titik berdiri penumpang ke titik tujuan. Maka sebagian masyarakat menganggap bahwa trayek angkutan umum tidak lagi mengakomodasi kebutuhan mereka. Alternatif lain menawarkan layanan yang dinilai lebih unggul oleh sebagian masyarakat dengan profesionalitas dan harga terjangkau.

2. Ekspektasi masyarakat terhadap layanan angkutan umum sangat tinggi baik pada kondisi fisik maupun non fisik. Sebagian besar masyarakat berekspektasi memperoleh layanan sopir dan kondektur yang professional disertai dengan kondisi kendaraan yang prima. Saat ini masih sangat banyak 
kondisi angkutan kota yang sudah tua dan berkarat, bahkan kinerja mesinnya juga tidak prima. Kini masyarakat berekspektasi lebih tinggi, mungkin karena telah melihat berbagai alternative transportasi umum lain yang lebih unggul.

3. Semakin masivnya pertumbuhan dan ekspansi bisnis transportasi berbasis aplikasi online (ojek dan taksi online). Perkembangan bisnis transportasi kini kian memuncak di kala aplikasi online menjamur di Indonesia. Masyarakat dihadapkan pada tawaran transportasi online dengan moda transportasi yang secara fisik masih baru, pengemudi yang bekerja secara professional dan promosi harga yang sangat menarik. Bahkan secara efisiensi dan ketepatan waktu dianggap memuaskan penumpangnya. Dengan demikian, angkutan umum dengan kelemahannya dari segi kondisi fisik dan non fisiknya menghadapi persaingan bisnis transportasi yang cukup berat dan harus segera ditangani. Jika tidak, maka perlahan angkutan umum akan punah.

Gambar 1. Alasan Anjloknya Bisnis Angkutan Umum

(Dari berbagai sumber)

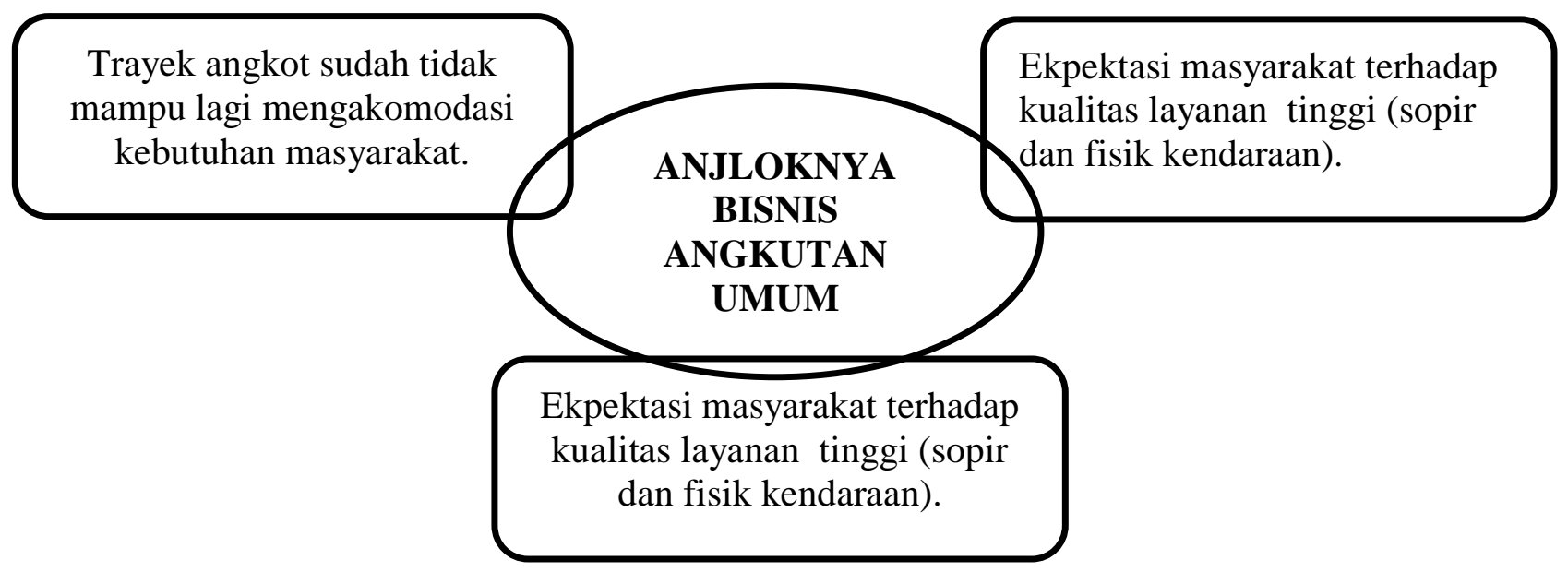

\section{Hambatan Pengelolaan Angkutan Kota}

Menurut Organisasi Angkutan Darat (Organda) dampak dari beberapa alasan yang telah disebutkan sebelumnya adalah banyak berkurangnya angkot di berbagai daerah. Berbagai solusi telah dilakukan oleh pemerintah, bahkan bekerja sama dengan pihak swasta untuk membangkitkan lagi angkot sebagai jantung transportasi umum kota. Namun belum menunjukkan hasil yang signifikan.

Beberapa hambatan yang dihadapi adalah:

1. Kondisi moda yang tidak memadai dari segi kualitas.
2. Dana yang dibutuhkan tidak sedikit.

3. Kerja sama stakeholder harus diperkuat agar program berkelanjutan.

4. Kebijakan dan aturan pemerintah yang mendukung dan melindungi angkot.

5. Tahapan peralihan moda yang harus terukur, karena peralihan moda membutuhkan adaptasi yang tidak sebentar.

Melihat kondisi demikian, maka masih adakah peluang bagi angkutan kota untuk bangkit? Tentu saja terbuka lebar. Inovasi seolah tak pernah mati, asalkan 
semua pihak yang terlibat dan mau beradaptasi dengan kondisi yang mungkin (untuk sementara) tidak nyaman. Terutama kenaikan tarif ojek atau taksi online yang kini terjadi setelah masa promosi awal berakhir, tidak sedikit juga dikeluhkan oleh penumpang. Dengan demikian dapat menjadi celah bagi pengusaha angkutan kota untuk bebenah Bersama dengan dukungan pemerintah dan pihak terkait lainnya. Tujuannya untuk menyediakan jasa angkutan umum yang memadai dan terjangkau bagi masyarakat.

\section{Solusi Pengelolaan Angkutan Kota Di Berbagai Daerah}

Pengelolaan angkutan kota telah dilakukan di berbagai daerah di
Indonesia guna mempertahankan dan meningkatkan angkutan kota sebagai moda transportasi unggulan di daerahnya. Dari pengurangan jumlah angkutan kota, modifitasi kendaraan, hingga kerjasama dengan pihak ketiga untuk menjadikan angkutan kota mampu bersaing di lingkungan bisnis transportasi umum yang terus berkembang dan berinovasi, serta ditunjang oleh kemajuan teknologi dan informasi digital.

Berikut ini akan disajikan berbagai pengelolaan angkutan umum di beberapa wilayah di Indonesia yang dapat menjadi referensi dalam pengelolaan angkutan kota di wilayah Kabupaten Bandung.

Tabel 2. Pengelolaan Angkutan Kota di Berbagai Daerah

\begin{tabular}{|c|c|c|c|}
\hline NO & PROGRAM & KOTA & KETERANGAN \\
\hline 1 & $\begin{array}{l}\text { Pengurangan Jumlah } \\
\text { Angkutan Kota }\end{array}$ & Bogor & $\begin{array}{l}\text { 1. Program penataan angkutan kota } \\
\text { dengan mengganti angkutan kota } \\
\text { lama menjadi moda yang lebih } \\
\text { besar daya tampungnya. } \\
\text { 2. Skema pertama konversinya adalah } \\
3 \text { angkutan kota menjadi } 2 \text { angkutan } \\
\text { kota. } \\
\text { 3. Sejak awal tahun } 2017 \text { Dishub Kota } \\
\text { Bogor mengkonversi angkot di } \\
\text { bawah 2005. dari } 3.412 \text { angkot } \\
\text { ditargetkan menjadi } 2.682 \text { angkot } \\
\text { saja. } \\
\text { 4. Contohnya pada Oktober } 2018 \text { lalu, } \\
\text { 30 angkot tidak beroperasi lagi (20 } \\
\text { angkot dihancurkan menjadi } \\
\text { potongan besi), } 10 \text { menjadi mobil } \\
\text { pribadi). Hasilnya berganti dengan } \\
20 \text { angkot modern. } \\
\text { 5. Skema lainnya konversi angkot } \\
\text { menjadi bus. } \\
\text { 6. Hambatannya adalah dana untuk } \\
\text { balik nama BPKB dan STNK, } \\
\text { selain itu juga kebanyakan angkot } \\
\text { BPKB nya jadi angunan bank atau } \\
\text { digadaikan, penjualan kendaraan tua } \\
\text { yang sulit. }\end{array}$ \\
\hline
\end{tabular}




\begin{tabular}{|c|c|c|c|}
\hline NO & PROGRAM & KOTA & KETERANGAN \\
\hline & & & $\begin{array}{l}\text { 7. Solusi untuk memenuhi kebutuhan } \\
\text { dana adalah mengandalkan } \\
\text { kerjasama iklan di bus (Rp. } 7 \\
\text { juta/th). }\end{array}$ \\
\hline 2 & Angkot Fest & Bogor & $\begin{array}{l}\text { 1. Konsepnya adalah memanfaatkan } \\
\text { jumlah angkot yang luar biasa } \\
\text { banyak di Bogor sebagai rebranding } \\
\text { Kota Bogor sebagai KOTA } \\
\text { ANGKOT STRATEGIS (disamping } \\
\text { ketidakuntungan yang diakibatkan } \\
\text { terlalu banyaknya angkot yang } \\
\text { menyebabkan kemacetan di Bogor). } \\
\text { 2. Tujuan Angkot Fest untuk } \\
\text { mengelola dan mengembangkan } \\
\text { SDM (sopir) angkot strategis. } \\
\text { 3. Angkot Fest berupa rangkaian } \\
\text { acara: Angkot Camp bagi sopir } \\
\text { angkot (diresmikan Sopir Angkot } \\
\text { Strategis-SAS), Angkot Award, } \\
\text { Angkot Art Festival (kampanye } \\
\text { kreatif dan modifikasi angkot) dan } \\
\text { Angkot Ngariung (forum angkot). } \\
\text { 4. Kritik: Tidak secara konkrit } \\
\text { memberi dampak terhadap bisnis } \\
\text { angkot dan dampak banyaknya } \\
\text { angkot di Kota Bogor (macet). } \\
\text { Namun diklaim menjadi awal } \\
\text { menuju program infrastruktur dan } \\
\text { manajemen tata kota untuk angkot. }\end{array}$ \\
\hline 3 & $\begin{array}{l}\text { Angkot Daring } \\
\text { Berbasis Aplikasi }\end{array}$ & Bekasi & $\begin{array}{l}\text { 1. Angkutan umum konvensional } \\
\text { beralih ke angkutan umum daring } \\
\text { berbasis aplikasi TRON. } \\
\text { 2. Diresmikan } 3 \text { Mei 2019. Sebagai } \\
\text { alternatif lain bagi pengguna } \\
\text { ojek/taksi daring akibat kenaikan } \\
\text { tarif ojek daring. } \\
\text { 3. Tarif murah hanya Rp 3.000,- } \\
\text { 2gerak lebih cepat karena tidak } \\
\text { 'mangkal' atau 'ngetem'. } \\
\text { 4. Mampu mengurai beban kemacetan } \\
\text { di Bekasi. } \\
\text { 5. Keamanan dan kenyamanan angkot } \\
\text { terpantau oleh Dinas Perhubungan } \\
\text { Kota Bekasi. } \\
\text { 6. Saat ini ada } 30 \text { unit angkot } \\
\text { TRON, target menggandeng } 1.000 \\
\text { angkot pada akhir } 2019 .\end{array}$ \\
\hline
\end{tabular}




\begin{tabular}{|c|c|c|c|}
\hline NO & PROGRAM & KOTA & KETERANGAN \\
\hline & & & $\begin{array}{l}\text { 7. Jika berhasil, maka PT TRON akan } \\
\text { diminta Pemkot Bekasi untuk } \\
\text { kerjasama mengelola Bus } \\
\text { Transpatriot. }\end{array}$ \\
\hline 4 & $\begin{array}{l}\text { Integrasi Transportasi } \\
\text { Antar Moda Jak } \\
\text { Lingko }\end{array}$ & DKI Jakarta & $\begin{array}{l}\text { 1. Pemerintah Provinsi DKI Jakarta } \\
\text { menargetkan seluruh angkutan } \\
\text { umum di Jakarta terintegrasi dengan } \\
\text { sistem Jak Lingko pada akhir } 2020 \\
\text { mendatang. } \\
\text { 2. Meliputi transjakarta, ANGKOT, } \\
\text { bus sedang hingga transportasi } \\
\text { berbasis rel (MRT dan LRT). } \\
\text { 3. Kelebihan ANGKOT terintegrasi } \\
\text { dengan sistem Jak Lingko: } \\
\text { a)Penghasilan sopir angkot yang } \\
\text { tetap (UMR), tidak perlu kejar } \\
\text { setoran, bahkan mendapat } \\
\text { jaminan kesehatan. } \\
\text { b) Angkot tidak ngetem. } \\
\text { c)Angkot taat peraturan lalu lintas. } \\
\text { d) Angkot tertib dalam menaikkan } \\
\text { dan menurunkan penumpang. } \\
\text { e)Penumpang merasa hemat, } \\
\text { nyaman dan aman. } \\
\text { f) Memudahkan penumpang karena } \\
\text { terintegrasi. } \\
\text { g) Kemacetan terurai karena } \\
\text { angkutan umum tidak ngetem } \\
\text { memenuhi jalan. }\end{array}$ \\
\hline 5 & $\begin{array}{l}\text { Usulan Organda } \\
\text { (Organisasi Angkutan } \\
\text { Darat) }\end{array}$ & Depok & $\begin{array}{l}\text { 1. Jumlah angkot di Depok semula } \\
2.784 \text { unit telah berkurang } \\
\text { setengahnya karena kalah saing } \\
\text { dengan transportasi berbasis } \\
\text { aplikasi online. } \\
\text { 2. Organda mengusulkan agar Angkot } \\
\text { beralih menjadi Angkutan Kawasan } \\
\text { berbasis aplikasi, yaitu melayani } \\
\text { door to door (depan rumah } \\
\text { penumpang). } \\
\text { 3. Pembayaran non-tunai. } \\
\text { 4. Sedang disiapkan } 4 \text { jenis angkot } \\
\text { ber-AC: angkutan medium } 3 / 4 \\
\text { dengan AC, angkutan kecil AC, } \\
\text { angkutan kawasan, dan angkutan } \\
\text { berupa bus wisata di Depok. }\end{array}$ \\
\hline
\end{tabular}

\section{Kesimpulan}

1. Berdasarkan dimensi tentang kualitas pelayanan angkutan kota yang 
disebutkan di atas antara lain keamanan, kenyamanan, kinerja \& kehandalan, kru dan kondisi kendaraan dan fasilitasnya. Artinya ada 5 (lima) aspek yang dinilai untuk mengetahui kualitas pelayanan angkutan kota, aspek keamanan dinilai dari keselamatan dalam perjalanan, keamanan dari tindakan criminal dalam perjalanan, serta keamanan dari perilaku penumpang lain. Sedangkan kenyamanan dilihat dari kenyamanan tempat duduk, tingkat kesesakan dalam kendaraan angkutan kota, dan kenyamannan temperature dalam kendaraan.

2. Berbagai Kota di Indonesia telah melakukan reformasi pada angkutan kota dengan berbagai respon yang berbeda oleh masyarakat.

\section{Daftar Pustaka}

1. A, Parasuraman. (2001). The Behaviorial Consequenses of Service Quality, Jurnal of Marketing, Vol 60.

2. Deddy Ritonga James A. Timboeleng, Oscar H. Kaseke (2015) Analisa Biaya Transportasi Angkutan Umum Dalam Kota Manado Akibat Kemacetan Lalu Lintas (Studi Kasus: Angkutan Umum Trayek Pusat Kota 45-Malalayang)

3. Dinas Perhubungan Kabupaten Bandung (2019) Studi Trayek Angkot Kabupaten Bandung

4. Sik Sumaedi, Gede Bakti, Medi Yarmen (2012) The empirical study of public transport passengers' behavioral intentions: The roles of service quality, perceived sacrifice, perceived value, and satisfaction (case study: Paratransit passengers in jakarta, indonesia), International Journal for Traffic and Transport Engineering (IJTTE) 2(1):8397 